\title{
Development of a Control Scheme for Grid Connected Solar Inverter
}

\author{
Aishwarya Banerjee, Tapas Kumar Saha, Mohd Afroz Akhtar
}

\begin{abstract}
Now-a-days the renewable energy sources (RES) are going under development, research and implementation to serve the civilization. Solar energy is the most easily available RES. A solar grid connected scheme, consists of the photovoltaic (PV) module, voltage step up converter, and DC to AC converter is discussed in this work. The control technologies like (i) maximum power point tracking (MPPT), (ii) grid synchronization and (iii) sinusoidal current injection into the grid are considered in this work. The Incremental Conductance (IC) technique is used here to attain the MPPT of the PV arrangement. A Second Order Generalized Integrator (SOGI) based PLL is developed to collect the grid voltage phase angle for synchronizing with the inverter. A Proportional-Resonant (PR) based controller is developed for regulating the exchange of power with the single phase grid as well as to reduce harmonic distortions in injected current.
\end{abstract}

Keywords: H-bridge inverter, Photovoltaic, Phase Locked Loop (PLL), Proportional Resonant (PR) controller

\section{INTRODUCTION}

In the modern age, the most important issue which is drawing the attention of human being is pollution. Renewable energy sources are helpful in reducing pollution. They are often described as a clean and green form of energy due to their minimal environmental impact in comparison to the fossil fuels. Among all the energies solar energy has proved to be very promising in its usefulness as a feasible, unfailing and environmentally friendly source of energy. Along with this more concern has been concentrated on linking between solar structure and power grid. Though voltage and current control schemes are achievable for the interconnection of the inverter and the grid, the current control scheme is generally preferred for its outstanding dynamic characteristics [1] and its built-in ability to limit the over-current.

The reliability of the grid connected inverter system depends on the topologies of converter and inverter. The topology that uses isolation transformer [2-3] can make the system bulky and a high-cost system compared to a transformer-less system. The losses of the transformer are also a considerable.

Various methods are suggested for the control of inverter output current [4-6] for injecting into grid. Like for the hysteresis current control scheme [4] though it is simple and robust it is having the disadvantages of variable switching

Revised Manuscript Received on August 22, 2019.

Aishwarya Banerjee, Department of Electrical Engineering, National Institute of Technology, Durgapur, India.

Tapas Kumar Saha, Department of Electrical Engineering, National Institute of Technology, Durgapur, India.

Mohd Afroz Akhtar, Department of Aero System Laboratory, Central Mechanical Engineering Research Institute, Durgapur, India. rate, current error, and high-frequency limitation. Another scheme is predictive current control, whose performance depends on the system model along with the reference current prediction [5-6]. There is a common issue of steadystate error in these schemes.

In the current control scheme, a Proportional Integral (PI) controller [7-8] is largely used. Here a Proportional Resonant (PR) controller is developed for the replacement of conventional PI controller used to control the inverter current. The PR controller can established an infinite gain at a particular fundamental frequency and therefore can make steady state error to zero. It can also track the reference sinusoidal signal perfectly. It also has good disturbance rejection capability than the PI controller [9].

For controlling the power transfer between the gridconnected inverter and the grid, the tracking of the fundamental component voltage phase angle is needed. To estimate the phase angle for grid synchronization Phase Locked Loop (PLL) is used. There are many methods [1011] present to achieve PLL. Though the T/4 delay PLL [12] is the simplest type for extracting phase angle. But they depend on the input signal time period so they are not suitable for single phase operations sensitive to frequency variation and voltage sag. To achieve the robustness with this type of PLL in frequency variation is a challenge. Single phase and three phase systems are used together in transmission and distribution of electricity. But single phase grid systems are having large array of application. They are considered as the most efficient ac power supply up to 1000 watts. They are having fewer design cost with simple design [13].

Here a grid connected solar inverter has analyzed along with the grid synchronization using SOGI based PLL, DC link voltage control with the help of a PI controller as well as the injected current control using a PR controller.

\section{SYSTEM DESCRIPTION}

\section{A. DC-DC Boost Converter and H-bridge Inverter}

A boost converter or step-up converter is a DC to DC converter which increases output voltage $\left(V_{\text {out }}\right)$ from its input voltage $\left(V_{i n}\right)$ according to the duty ratio $(d)$ of gate pulse applied to the switch. As the power must be conserved so the output current is less than the source current. In boost converter, the voltage increases because of the tendency of the inductor to withstand the changes in current by strengthening and weakening the magnetic field. It is a type of switch mode power supply. 


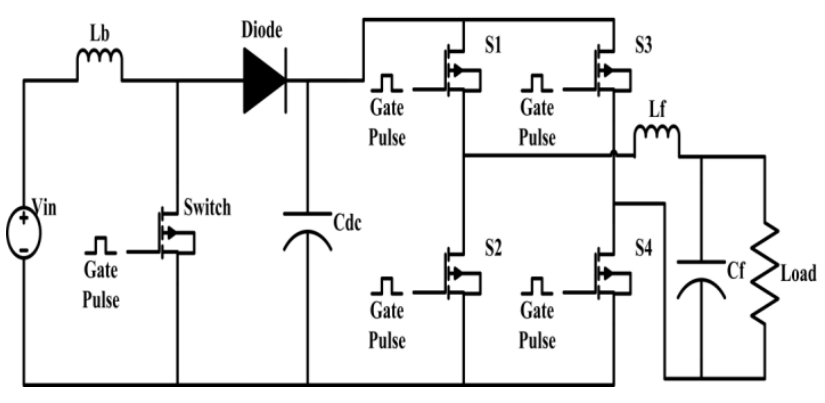

Fig 1: Schematic diagram of the power circuit

It can get the power from any kind of DC sources like batteries, solar panel, rectifier, and DC generators. An inverter is a power electronics device or circuitry which converts DC to AC. The input and output voltage, as well as the power handling, depend upon the design of the circuit. It does not have any power producing capability; the power is supplied by the DC source. For supplying the pulses to the switches of the inverter, the bipolar modulation technique is used. The schematic diagram is shown in Fig 1.

\section{CONTROLLER DESIGN}

\section{A. Outer Voltage Loop}

The voltage generated by the Renewable Energy Sources (RES) varies with the environmental conditions. This leads to a variation in the DC-link capacitor $\left(\mathrm{C}_{\mathrm{dc}}\right)$ voltage connected between boost converter and inverter. But this voltage has to be maintained constant as it will be supplied to the inverter as input. The inverter will supply AC power into the grid by injecting sinusoidal current proportional to the power delivered to the DC-link capacitor. When the inverter is tied with grid the output voltage is constant. Hence current injected into grid rely on the available power at DC link capacitor. So the DC link voltage is controlled according to output power. This voltage loop is controlled by a PI controller shown in Fig 2 .

Transfer function of PI controller is $G_{c v}(s)$.

The plant transfer function is

$$
G_{c v}(s)=K_{p}+\frac{K_{i}}{s}
$$

$$
G_{p}(s)=\frac{1}{C s}
$$

Where $\mathrm{Kp}$ is the proportional gain and $\mathrm{Ki}$ is the integral gain. Their values are 0.3 and 12 respectively. Gain margin is infinite, Phase margin is 107 degree and phase crossover frequency is $3.8 \pi \mathrm{rad} / \mathrm{sec}$. The characteristic graph of the PI controller is shown in Fig 3.

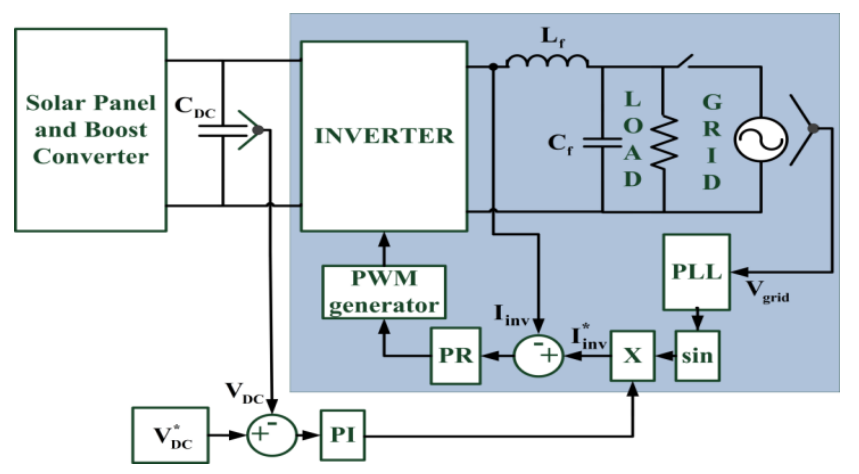

Fig 2: Control scheme containing outer voltage loop and inner current loop

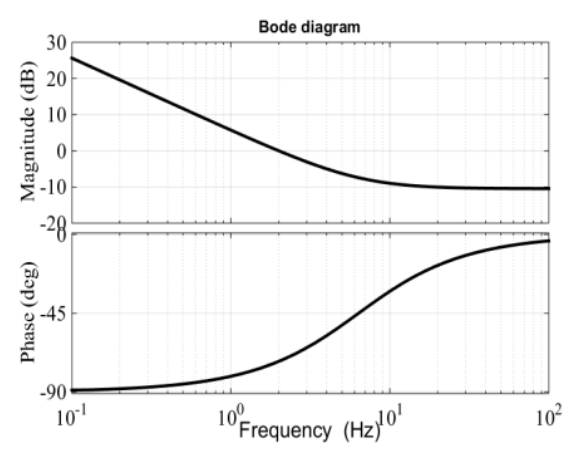

Fig 3: Bode Plot of the PI controller

\section{B. Inner Current Loop}

For controlling the injected current a PR controller is taken because a PI controller is unable to track any sinusoidal reference signal perfectly without steady state error both for magnitude and phase. Also, it can bring an infinite gain at the fundamental frequency so it can have a steady state error of zero. The controller present in the inner current loop generates a variable voltage which is fed into the pulse width modulator (PWM) to produce switching signal for H-bridge inverter. The inner current loop is shown in Fig 2 within box.

$G_{p}(s)$ is the plant transfer function.

$$
G_{p}(s)=\frac{V_{d c}}{s L_{f}+r_{L}}
$$

Transfer function of the PR controller is $G_{c c}(s)$.

$$
G_{c c}(s)=K_{p}+\frac{2 K_{i} \omega_{c} s}{s^{2}+2 \omega_{c} s+\omega_{0}^{2}}
$$

Where $\mathrm{Kp}=0.405$ is the proportional gain, $\mathrm{Ki}=30$ is the integral gain, $\omega_{0}=100 \pi \mathrm{rad} / \mathrm{sec}$ is the fundamental frequency and $\omega_{c}=3.184 \pi \mathrm{rad} / \mathrm{sec}$ is the cut off frequency. Phase margin is infinite, gain margin is 116 degree and phase crossover phase frequency is $126 \mathrm{~Hz}$. The characteristic graph of the PR controller is shown in Fig 4.

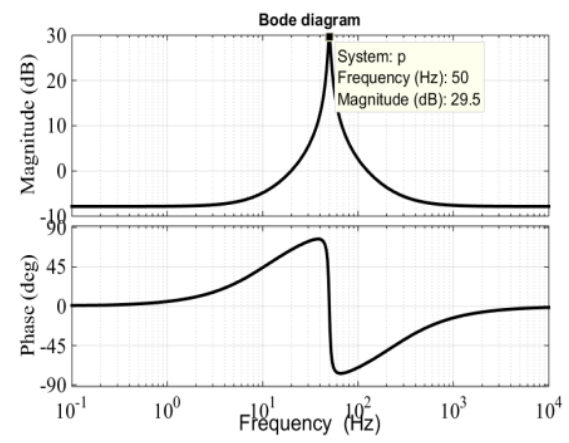

Fig 4: Bode Plot of PR controller

\section{DESCRIPTION OF PHASE LOCKED LOOP (PLL)}

PLL has three parts like a phase detector, loop filter, and voltage controlled oscillator. There are various types of PLL exist, among them, the Second Order Generalized Integrator (SOGI) based PLL is followed here which based on adaptive filtering to create the orthogonal signal generation system. In the phase detector Park's transformation is used for detecting phase error, as follows: 


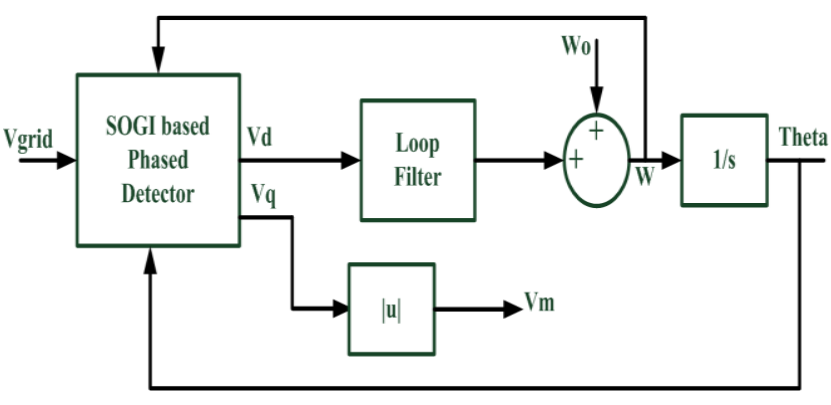

Fig 5: Second Order Generalized Integrator (SOGI) PLL

$$
\left(\begin{array}{l}
v_{d} \\
v_{q}
\end{array}\right)=\left(\begin{array}{cc}
\cos \theta^{\prime} & \sin \theta^{\prime} \\
-\sin \theta^{\prime} & \cos \theta^{\prime}
\end{array}\right)\left(\begin{array}{l}
v_{\alpha} \\
v_{\beta}
\end{array}\right)
$$

Where, $v_{g}=v_{\alpha}=V_{m} \sin \theta$

And $v_{\beta}=V_{m} \cos \theta$

$V_{g}$ is the grid voltage or input to the PLL and $v_{\beta}$ is the generated orthogonal signal.

Putting the values of $v_{\alpha}$ and $v_{\beta}$ the value of $v_{d}$ (direct axis voltage) and $v_{q}$ (quadrature axis voltage) is achieved as follows:

$$
\left(\begin{array}{l}
v_{d} \\
v_{q}
\end{array}\right)=\left(\begin{array}{c}
V_{m} \Delta \theta \\
-V_{m}
\end{array}\right)
$$

Table I. Simulation parameters of the SOGI-PLL

\begin{tabular}{lc}
\hline Parameters & Values \\
\hline Input Voltage Amplitude & $\mathrm{V}_{\mathrm{m}}=200 \sqrt{2}$ \\
Input Voltage Frequency & $\omega_{0}=50 \mathrm{~Hz}$ \\
PI Controller Parameters & $\mathrm{K}_{\mathrm{p}}=0.35, \mathrm{~K}_{\mathrm{i}}=13.6$ \\
Cut Off Frequency & $\omega=50 \mathrm{~Hz}$ \\
Control Parameters & $\mathrm{K}_{\mathrm{a}}=160, \mathrm{~K}_{\mathrm{e}}=1.414$ \\
\hline
\end{tabular}

The waveform of the extracted phase angle is shown in Fig 6 along with the input signal to show that the phase angle is following the phase of the input signal properly.

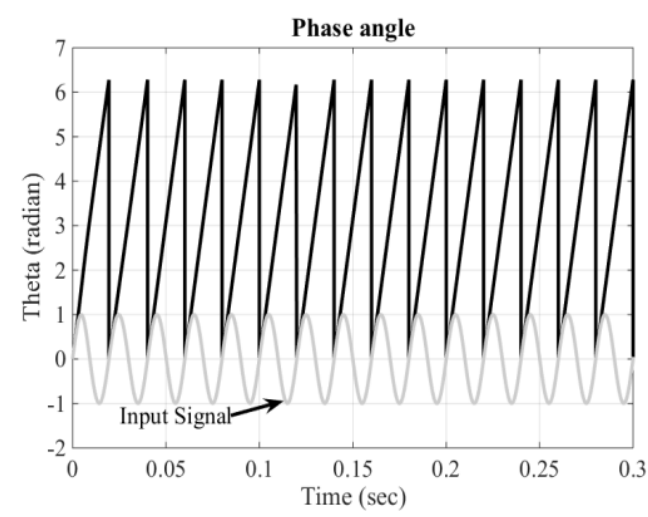

Fig 6: Extracted phase angle and the input signal to PLL

\section{EXPERIMENTAL RESULTS}

\section{A. Simulation Results}

The simulation results are shown to validate the overall performance of the converter and the implemented control algorithm. The complete model of power electronics interface is developed on the Matlab/Simulink platform with a simulation time of 1 microsecond.

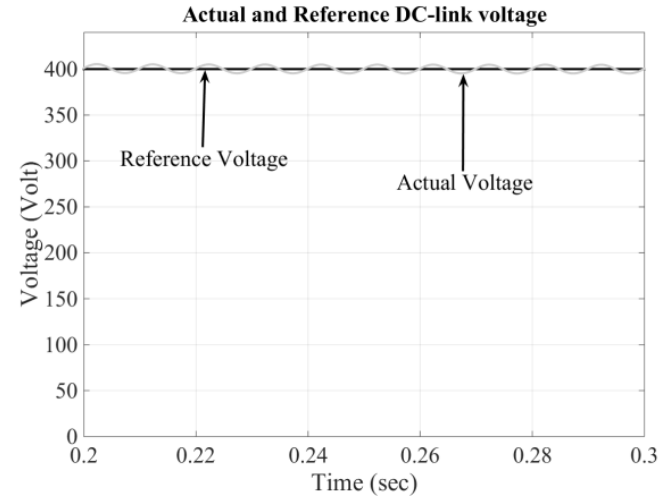

Fig 7: Actual and reference voltage in Volts

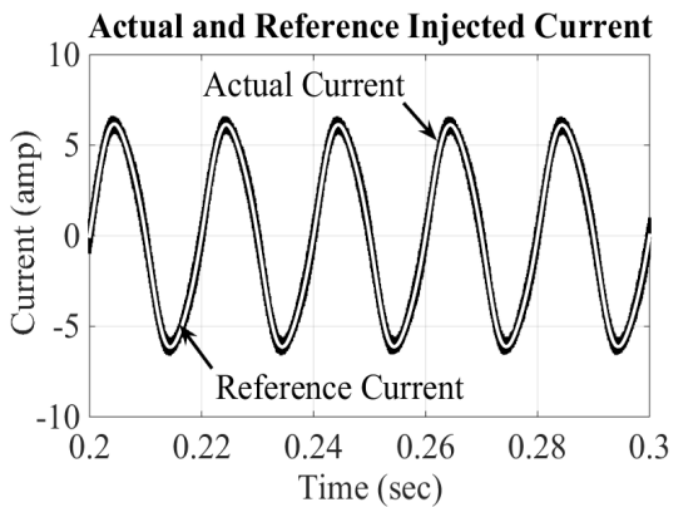

Fig 8: Actual and reference injected current in Ampere

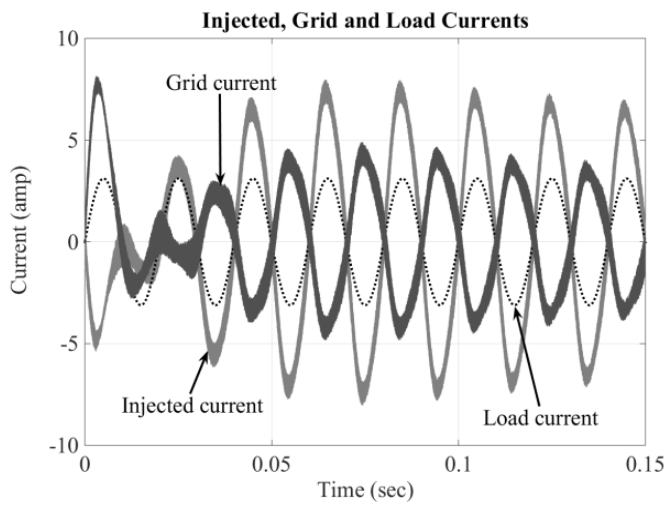

Fig 9: Injected current, Grid Current and Load Current in ampere

The grid is simulated with an AC voltage source tied with inverter. The DC link capacitor is precharged to 390 Volts, for reducing the problem of inrush current. The ripple across the capacitor is near about 9 Volts. The performance of controllers is shown in Fig 3 and 4. Variation in the injected current, grid current and load current is presented in Fig 9.

Reference DC link voltage is given 400 Volts. The voltage is settling at $0.1 \mathrm{sec}$ with $2.25 \%$ ripple in voltage. The injected current is following the reference current perfectly. Current is settling at $0.15 \mathrm{sec}$.

The injected current represents the addition of the grid current and load current. When the inverter is injecting the current into the grid it is having a 180-degree phase shift compared to the injected and load current.

\section{Published By:}




\section{Development of a Control Scheme for Grid Connected Solar Inverter}

From Fig 9, it can be seen that after $0.03 \mathrm{sec}$ the transient is over and the grid is absorbing power. Therefore it is clearly observed that the controllers are achieving the desired performance successfully retaining the output current and voltage at their respective reference values.

\section{B. Hardware Results}

The hardware validation of inverter in open loop is done successfully. The switching pulses for the inverter are generated with the help of dSPACE 1104 controller board with $20 \mathrm{kHz}$ switching frequency and $50 \%$ duty ratio. The input voltage supplied to the inverter is 48 volts. A 50 ohms resistance is connected as load giving the output voltage 23.3 volts.

The complete circuit of the PLL topology is also verified using the dSPACE 1104 controller board. These circuits are implemented on MATLAB/Simulink platform in a PC interfaced with the controller board. The hardware setup for the experiments of the inverter in open loop and PLL are presented in Fig 10 and Fig 11 respectively. Hardware results are presented in Fig 12, 13 and 14 respectively. From Fig 14 it is observed that the extracted phase from the PLL is same as the phase of the grid voltage.

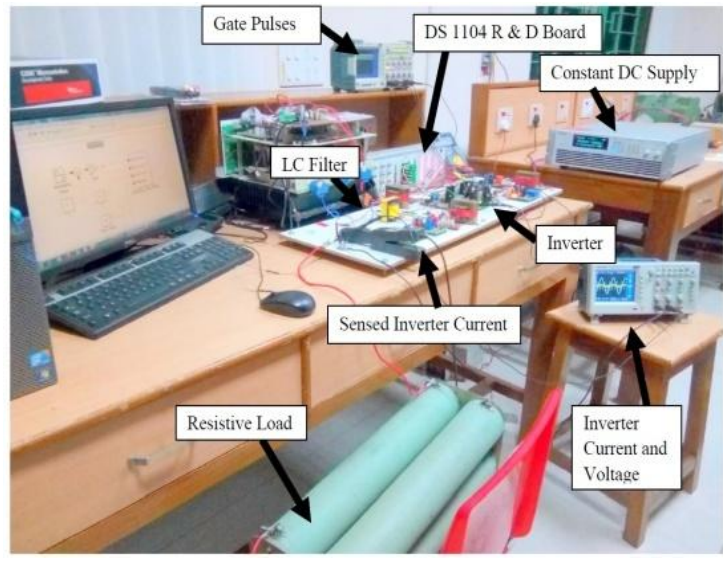

Fig 10: Complete hardware setup of the inverter in open loop with resistive load

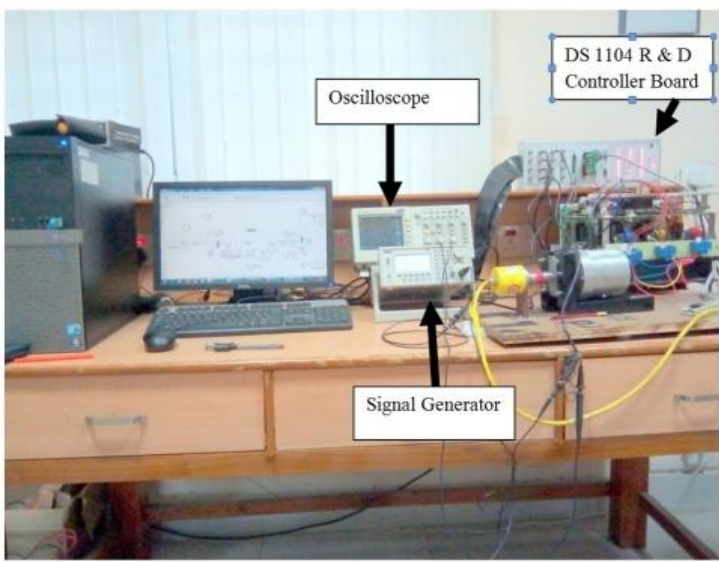

Fig 11: Hardware setup for PLL

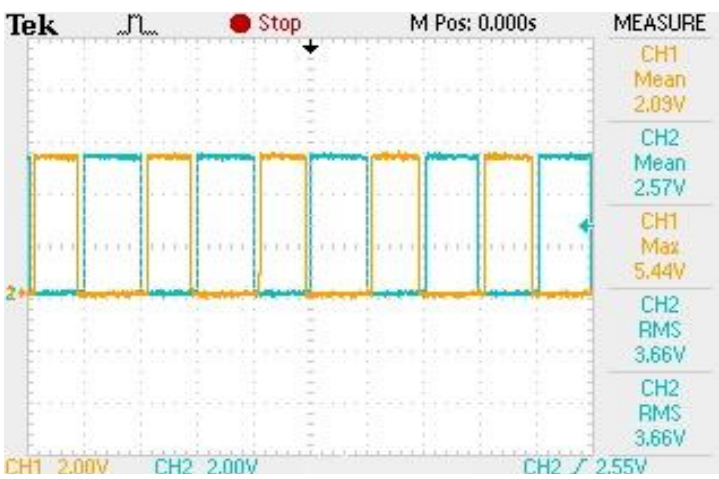

Fig 12: Gate pulse supplied to the inverter switches

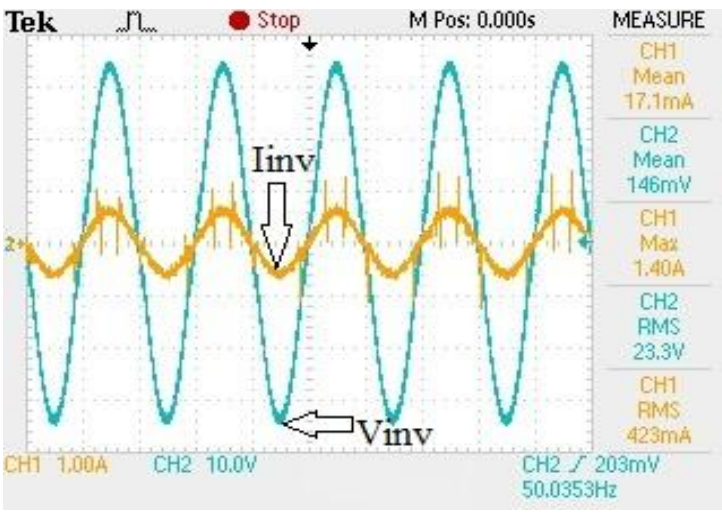

Fig 13: Inverter current (ampere) and voltage (volts)

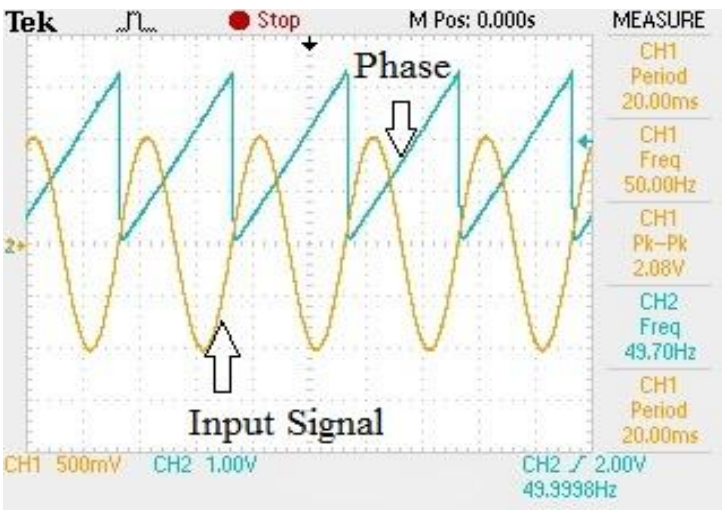

Fig 14: Input signal and extracted phase angle

\section{CONCLUSION}

Here the complete grid-connected inverter is studied and simulated with a Photovoltaic (PV) module as a source in MATLAB Simulink. The performance of the control scheme is discussed and the results are presented. Power delivered to grid is controlled with the help of the outer voltage control loop and the inner current control loop. Performance of PLL is also good as it gives the appropriate frequency information of the grid voltage. Proportional Resonant controller and Proportional Integral controllers are also giving a successive performance which is observed from the presented results. Both voltage and current is tracking the references perfectly. 
The various current waveforms such as inverter current, grid current, and load currents are shown and analyzed. Switching pulse for the H-bridge inverter is generated with the help of MATLAB and dSPACE controller board (DS 1104). The PLL topology is also verified with the help of this controller board and the required waveforms are presented. Hardware experimental setups for the inverter as well as PLL are also presented along with their resulting waveforms.

\section{ACKNOWLEDGMENT}

The authors would like to acknowledge to the authorities of National Institute of Technology, Durgapur and Central Mechanical Engineering Research Institute, Durgapur for helping to perform the research presented in this paper.

\section{REFERENCES}

1. Ali Algaddafi, Saud A. Altuwayjiri, Oday A. Ahmed, and Ibbrahim Daho "An Optimal Current Controller Design for a Grid Connected Inverter to Improve Power Quality and Test Commercial PV Inverters" in The Scientific World Journal (2017)

2. Yaosuo Xue, Liuchen Chang "Topologies of single-phase inverters for small distributed power generators." In IEEE (2004)

3. Mohd. Afroz Akhtar. "Development of Micro Inverter using Phase Modulated Converter". Lambert Academy Publishing (2012)

4. R. D. Lorenz, T. A. Lipo, and D. W. Novotny, "Motion control with induction motors", vol. 82, iss. 8, pp. 1215-1240. in Proc. IEEE (1994)

5. A. Kotsopoulos, J. L. Duart, M.A.M Hendrix, "A predictive control scheme for DC voltage and AC current in grid-connected photovoltaic inverters with minimum DC link capacitance", in The 27th annual Conference of the IEEE Industrial Electronics Society, vol.3, pp. 1994-1999, (2001).

6. D. G. Holmes and D. A. Martin, "Implementation of a direct digital predictive current controller for single and three-phase voltage source inverters", IAS Annu. Meeting, pp. 906-913. in Proc. IEEE 1996

7. Hanju cha.Trung-Kien $\mathrm{Vu}$, Jae-Eon Kim. "Design and Control of Proportional Resonant Controller Based Photovoltaic Power Conditioning System." IEEE.2009

8. Daniel Zammit, Cyril Spiteri Staines, Maurice Apap, John Licari. "Design of Proportional Resonant Current Control with Selective Harmonic Compensators using MATLAB."In Journal of Electrical systems and Information Technology.2017

9. Remus Teodorescu, Frede Blaabjerg, Marco Liserre. "Proportional Resonant Controllers. A new Breed of Controllers.'In Journal of Electrical Engineering.2004

10. Youngheng Yang, Frede Blaabjerg. "Synchronization in Single-Phase Grid-Connected Photovoltaic Systems under Grid Faults" IEEE.2012

11. Mohammad Monfared, Saeed Golestan. "Control strategies for singlephase grid integration of small-scale renewable energy sources: A review" 2012

12. Abhishek. R, Ashrith. N, Arjun. N, Akshatha Rao. I. L. "Measurement of phase angle Using a Phase Locked Loop" in IJEED.2012

13. Andrew Hintz, Rajagopal Prasanna "Comparative study of three phase grid connected inverter sharing unbalanced three phase or single phase load.” In IEEE.2015

\section{AUTHORS PROFILE}

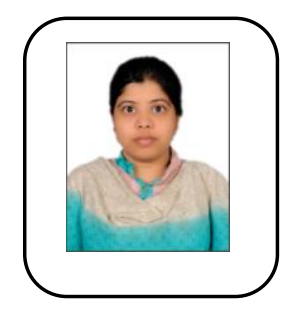

Aishwarya Banerjee She received the B. Tech. degree in electrical engineering from Bengal College of Engineering and Technology for Women, Durgapur, India, in 2016, the M.E. degree in Power Electronics and Machine Drives from National Institute of Technology, Durgapur, India, in 2018. Her current research interests include power electronics, renewable energy, grid connected solar inverters and machine drives.

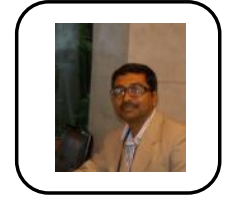

Tapas Kumar Saha $\mathrm{He}$ received the B.E degree in electrical engineering from Jalpaigur Government Engineering College, University of North Bengal, Jalpaiguri, India, in 1997, the M.E. degree in electrical machines from Jadavpur University, Kolkata, India, in 1999, and the Ph.D. degree from the Electrica Engineering Department, IIT Kharagpur, Kharagpur, India, in 2009. He is currently a Professor with the Department of Electrical Engineering, National Institute of Technology at Durgapur, Durgapur, India. His current research interests include machine drives, power electronics, renewable energy, and the grid integrated distributed generations.

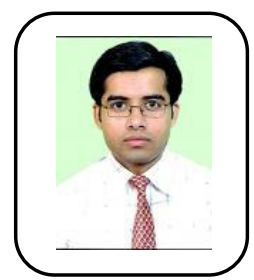

Mohd Afroz Akhtar He received the B. Tech degree in electrical engineering from Jamia Millia Islamia, New Delhi, India, in 2010, the M. Tech degree in Mechatronics in 2012 and persuing Ph.D. degree from AcSIR, New Delhi. He is scientist at Council of Scientific and Industrial Research, India doing research in the field of Power Electronics in electric vehicle and renewable energy. 